\title{
False aneurysm of the ascending aorta with aortico-right atrial fistula
}

\author{
SA PHOTIOU, TK KAUL, JL MERCER \\ From the Regional Cardio-Thoracic Surgical Centre, Broadgreen Hospital, Liverpool
}

False aneurysm of the ascending aorta is an unusual surgical complication which has been described as arising from the aortic cannulation site, ${ }^{12}$ from a needle puncture site $^{34}$ and the aortic suture line. Untreated cases are liable to develop complications similar to those described for aneurysm of the sinuses of Valsalva. ${ }^{5}$ This report deals with a case of false aneurysm of the ascending aorta, with aortico-right atrial fistula, arising from the aortic suture line after aortic valve replacement. The problems associated with the management of such a lesion are discussed.

\section{Case report}

A 55-year-old man underwent aortic valve replacement on 18 January 1979. Cardiopulmonary bypass was established by cannulation of the ascending aorta and cannulation of both venae cavae. The aortic valve was heavily calcified and was replaced with a $27 \mathrm{~mm}$ Björk-Shiley prosthesis, using interrupted 2/0 Ethibond sutures. The aortotomy was closed with continuous $2 / 0$ Prolene. The postoperative period was uneventful apart from heavy drainage from the mediastinal drains, amounting to 1630 $\mathrm{ml}$ in the first 24 hours, which ceased spontaneously. The patient made a satisfactory recovery and remained well for 10 months when he developed increasing dyspnoea on exertion and was found to have a loud continuous murmur over the whole of the precordium, maximal at the left sternal edge. Angiocardiography and cardiac catheterisation performed on 21 December 1979, showed a large false aneurysm arising from the ascending aorta and a fistulous communication into the right atrium (figure) with a left to right shunt of $1 \cdot 6 / 1 / \mathrm{min}$. The aortic prosthesis was functioning normally.

The patient underwent operation on 17 January 1980. The left groin was prepared for femoral arterial cannulation. A major haemorrhage occurred when an attempt was made to divide the sternum, as the false aneurysm had eroded it. Rapid cooling to $28^{\circ} \mathrm{C}$ was achieved by femoral arterial perfusion, the return being predominantly from the aneurysm. The sternum was then widely opened and the haemorrhage into the aneurysmal sac was controlled by the insertion of a size 16 Foley catheter through the fistulous opening into the aorta and inflation of the balloon to obliterate the orifice. A venous cannula was inserted through a second fistulous opening into the right atrial appendage. Further cooling to $20^{\circ} \mathrm{C}$ was then carried out using the return from the venous cannula.

Address for reprint requests: Mr JL Mercer, Regional Cardio-Thoracic Surgical Centre, Broadgreen Hospital, Liverpool L14 3LB.
For the location of the defects and their repair, perfusion flow was temporarily reduced to a minimum and the patient was placed in the Trendelenburg position to avoid cerebral air embolism.

The defect in the ascending aorta was about $1 \mathrm{~cm}$ in diameter and was found to have originated at the site of the previous aortic suture line. It was repaired in two layers using interrupted $3 / 0$ Mersilene with Teflon buttresses and continuous 2/0 Prolene. During re-warming the aneurysmal sac was partially dissected and excised. The patient reverted to sinus rhythm and was weaned from the bypass without difficulty. The opening into the right atrial appendage was then repaired using two purse string sutures of $2 / 0$ Prolene.

Bacteriological cultures from the wall of the aneurysm were negative. Recovery was uneventful, and the patient has remained well since re-operation without evidence of recurrence of the false aneurysm.

\section{Discussion}

Postoperative false aneurysm of the ascending aorta is known to arise from the aortic cannulation site after mediastinal infection ${ }^{6}$ but, more rarely, in the absence of infection, it may arise from the aortic suture line after

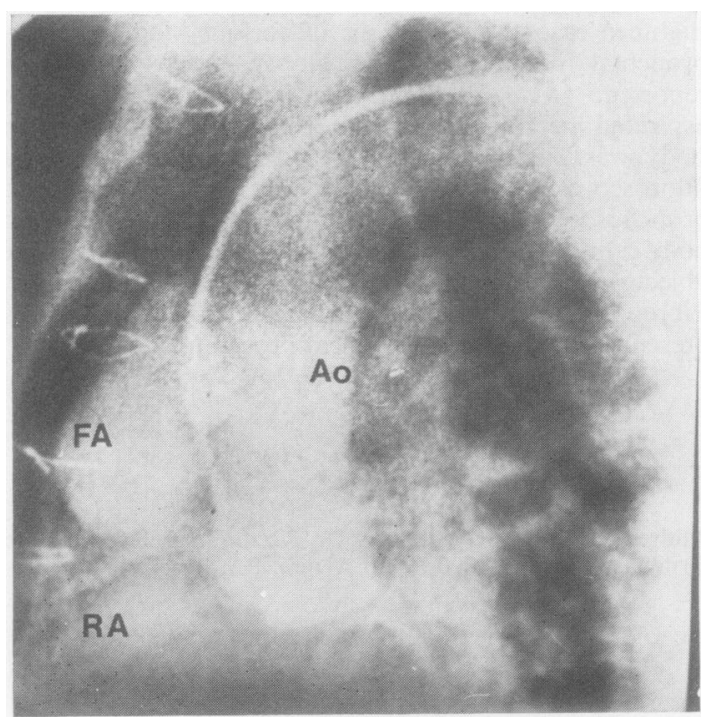

Figure False aneurysm of the ascending aorta with aortico-right atrial fistula. Ao $=$ aorta, $F A=$ false aneurysm, $R A=$ right atrium. 
aortic valve replacement, ${ }^{4}$ from aortic needle puncture, ${ }^{34}$ aortic cross-clamping, ${ }^{3}$ and aortic cannulation. ${ }^{12}$ Whatever the causative factor, the pathogenesis of the lesion is the same-after a breach in the aortic wall a haematoma is formed, the extravasated blood undergoes organisation peripherally and lysis within, so that a cavity persists, communicating with the aortic lumen. Late bleeding from the aortic suture line occurs more frequently than is recognised. ${ }^{4}$ In our case, the false aneurysm was found to have originated from the aortic suture line and then to have established communication with the overlying right atrial appendage. A similar case does not seem to have been previously reported, although aortico-right atrial fistula has been reported after rupture of a sinus of Valsalva aneurysm ${ }^{4}$ and from dissecting aneurysm of the ascending aorta. ${ }^{7}$ Our patient presented with a left to right shunt and increasing dyspnoea. These patients are also prone to infective endocarditis and the prognosis of untreated cases is generally poor. ${ }^{5}$

During the repair of such defects the surgeon is faced with the problem of exsanguinating haemorrhage from accidental entry into the aneurysm when performing the sternotomy, mobilising the sac or retracting the sternum. ${ }^{1}$ It is often impossible to mobilise the ascending aorta for cross clamping. Tearing of the right coronary artery during sternal spreading has also been described. ${ }^{1}$ Elective peripheral cannulation, limited cardiopulmonary bypass, and circulatory arrest under deep hypothermia have been shown to be valuable. ${ }^{2}{ }^{6}$ In our case the haemorrhage into the aneurysmal sac was controlled by the insertion and inflation of a Foley balloon catheter into the aortic fistulous opening. Deep hypothermia was rapidly achieved by femoral perfusion and venous drainage from the right atrium. A limited period of circulatory arrest is usually necessary for the identification and repair of the fistulous openings, since a dry field is difficult to achieve without aortic cross-clamping. ${ }^{1}$ Maintenance of minimal perfusion and a Trendelenburg position of the patient are helpful in preventing cerebral air embolism during the closure of the aortic fistulous communication. ${ }^{4}$

\section{References}

${ }^{1}$ Branchini B, Zingone B, Vaccari M. Ascending aortic false aneurysm following cannulation for perfusion. Thorax $1976 ; 31: 234-7$.

${ }^{2}$ Flick WF, Hallermann FJ, Feldt RH, Danielson GK. Aneurysm of aortic cannulation site and successful repair by means of peripheral cannulation, profound hypothermia and circulatory arrest. J Thorac Cardiovasc Surg 1971;61:419-23.

${ }^{3}$ Eliot RS, Levy MJ, Lillehei CW, Edwards JE. False aneurysm of the ascending aorta following needle puncture and cross clamping. J Thorac Cardiovasc Surg 1964; 47:248-53.

${ }^{4}$ Windsor HM, Shanahan MX. Unusual aneurysms of the root of the aorta. J Thorac Cardiovasc Surg 1967;53: 830-6.

${ }^{5}$ Swayers JL, Adams JE, Scott HW Jr. Surgical treatment for aneurysms of the aortic sinuses with aortico-atrial fistula. Surgery 1957;41:26-42.

${ }^{6}$ Lillehei CW, Todd DB, Levy MJ, Ellis RJ. Partial cardiopulmonary bypass, hypothermia, and total circulatory arrest. A life saving technique for ruptured mycotic aortic aneurysms, ruptured left ventricle and other complicated cardiac pathology. $J$ Thorac Cardiovasc Surg 1969;58:530-44.

${ }^{7}$ Holmes EC, Brawley RK, Fortuin NJ, White RI Jr. Rupture of dissecting aneurysm of thoracic aorta into the right heart chambers. J Thorac Cardiovasc Surg 1974;68: 611-4. 